of the potential users, and a technical person who understands the general ways technology can be useful.

The relevant expertise of EM providers includes use of central knowledge resources and forms of telemedicine. It also includes heavy experience in multitasking, rapid distillation of key data, and efficient communication. Each of these is an information processing task that can be augmented by the use of technology. An EM provider or group who can understand these processes in a systems model, and who can clearly communicate the information transactions that occur, will be able to specify the truly beneficial information systems of the future; no one else will be as effective in bringing new tools into our workplace. If such a person also carries a working knowledge of effective technology paradigms, the task will be that much easier.

\section{CONCLUSIONS}

Information systems offer tremendous value to EM practice and research. In order for us to realize this value, we must effectively merge clinical and technical expertise in the design of new applications. Integration and use of standards at many levels are of vital importance, so that data are available where needed, regardless of where the data are entered. Information systems should be selected to support both research and practice use; this will enhance the strength of the research effort, and conversely will improve practice by offering guidance based on solid evidence.

National organizations can help the specialty grow around the use of information. Education is needed to develop workers skilled in data management and analysis, who can translate the needs of the clinicians to the skills of the engineers. Education is also needed to ensure that EDs everywhere understand the current state of information systems, the features that can be most useful to them, and the trends of the near future. This education can come as part of residency and fellowship training for general knowledge, and through academic journals for communicating new concepts in information management and technology.

\section{REFERENCE}

1. Cordell WH, Overhage JM, Waeckerle JF, for the Information Management Work Group. Strategies for improving information management in emergency medicine to meet clinical, research, and administrative needs. Acad Emerg Med. 1998; 5:162-7.

Key words: research; emergency medicine; outcomes: informatics; information systems; emergency department.

\title{
Further Thoughts on Research Funding
}

\author{
Michael W. Mulholland, MD, PhD
}

\begin{abstract}
- In Part I of the Proceedings of the Future of Emergency Medicine Research Conference, Carden et al. addressed strategies for enhancing support of research in emergency medicine (EM), ${ }^{1}$ and Biros et al. addressed means for developing the re-
\end{abstract}

search infrastructure in the specialty. ${ }^{2}$ This commentary expands further upon those concepts.

Research funding is a challenge for every investigator in every specialty. It does not occur unless there is a well-planned, deliberate effort. It

From the University of Michigan Medical Center, Ann Arbor, MI. Department of Surgery $(M W M)$.

Received: November 11, 1997; accepted: November 12, 1997.

Prior presentation: Future of Emergency Medicine Research Conference, Washington, DC, March 1997.

Address for correspondence and reprints: Michael W. Mulholland, MD, PhD, University of Michigan Medical Center, 2920 Taubman Health Care Center, 1500 East Medical Center Drive. Ann Arbor, MI 48109-033J. Fax: 313-936-5830; e-mail: micham@umich.edu

This article is being copublished in Academic Emergency Medicine and the Annals of Emergency Medicine. (C) 1998 by Hanley \& Belfus, Inc.

requires an individual commitment, but equally requires an academic department to be organized and supportive. Essentially, it is a matter of priorities.

\section{THE IMPACT OF RESEARCH}

There are 3 questions that an academic department has to answer for itself before it decides on a strategy to use to become a research-oriented department. The first question is "Is investigation an institutional/departmental priority?' A number of things must be considered. Is there an ethic of inquiry? Is this part of the reason the department exists? Is that part of the job expectation of every member of the faculty? That expectation can 
be imposed on faculty by the chief, but it usually does not work best that way. It needs to come from within. The people that join the faculty need to do so because that's what they want to do with their lives. In addition to having expectations, there need to be rewards for it. We can talk about promotion and tenure as a reward, but it amounts to money, because your kids do not care about your tenure. So, the first thing is to decide whether this is really important.

The second very crucial question is what form shall the research take? Most departments concentrate on traditional laboratory research or functional health services research. My own bias is that for most departments of EM, it should probably be the latter. It fits better with the interests and talents of emergency physicians and also fits better with what you do clinically for a living. The form of research emphasized by a department also is an institutional question that has to be addressed, and it dictates the infrastructure you need. For bench research, the infrastructure is more expensive. You need a laboratory, which includes a lot of buildings, laboratory rooms, and offices. The equipment needed for modern biomedical research is quite expensive. Generally an animal facility and a lot of backup (e.g., veterinary care) are needed.

If the choice instead is for health services research, then the infrastructure requirement is different. The "laboratory" is as important, and an extensive informatics system is the research tool. Collaborators are even more important in even greater variety. In addition to physicians, a successful team will need epidemiologists, economists, computer experts, and many other people who may not have an obvious relationship to medicine.

The third question that you need to ask is "Will faculty research experiences be reflected in training opportunities?" At the University of Michigan, we have set up our training program explicitly to give residents a research experience as part of their residency. That echoes all the way through how the faculty members live their lives and how the institution is set up. It means that we are seeking to train other institutions' faculty members. We do not explicitly say this to our residents, but that is the message we give; i.e., what we are really trying to do is train people who will go into academic medicine or surgery somewhere else, and about half of them do.

This philosophy impacts on resident selection and the kinds of people who will apply to your institution. It also impacts the residency structure because the trainees have to leave clinical training for an allotted period of time. All the general surgery residents who come to our program are allowed 2 years of training in the investigative field without clinical responsibilities. The normal 5-year surgery residency is automatically 7 years in length, and the applicants know that coming into the program.

In addition to the time commitments, there are big financial implications to extending a training program because we have support for only 5 clinical years. There is a requirement to obtain money through various ways to fund the trainees' salaries, such as training grants, philanthropy, and endowments.

\section{EXTRAMURAL FUNDING}

The next challenge is to obtain extramural funding. Having a professional person help you with this process is crucial. All of us think we know what we want to do, but we do not have a good handle on, e.g., personnel and finance issues. Who will handle the technicians, who will be likely to get the promotion, and so on? A lot of indirect costs are going to be applied to this grant. What kind of institutional rules go into this? Professional help with other ancillary issues such as institutional review board rules, human subjects use and animal use are often neglected. Professional help is essential to overcome these roadblocks.

When moneys are awarded, professional oversight of expenditures is also essential. In spending award grants, there are certain requirements about how funds can be used. It is a moving target. You need to run out of money precisely at the end of the grant time. I think that is best done professionally. For big departments, this should be done in-house. The department of surgery at Michigan has 90 faculty members and $45 \%$ are externally funded through research. We have lots of grants and we have 3 people who manage just this. One person helps with the grant operation, one with the grant expenditures, and another with all of the other little things in-between. For smaller departments who do not have enough grants yet to justify this, almost every medical school and central administration has professionals to help with grant management.

An essential element for success is a panel of funded investigators. Throughout the medical school, there will be funded people in the medical school faculty. You should use them for 3 different tasks.

1. You should use them to train your future faculty members. For example, if you have a talented resident who wants to do a particular form of research, send him or her out of your department. Have the resident get the benefits of a successful person's insights.

2. Funded investigators should also be enlisted in mentoring new faculty. At Michigan, before we hire a surgeon who is interested in research, we identify a mentor and ask that person, who is often not in our department, to recruit the surgeon. When he or she is hired, we then ask that person to mentor the faculty member, who gets a report card from that outside mentor, as well as from the surgical mentors. 
3. Your panel of investigators should help you in targeting areas of investigation, identifying funding opportunities, and predicting the future. When writing grants, they can help by editing, and when submitting manuscripts, they can help by making a paper look professional.

The next essential element, and perhaps the most difficult, is monetary flexibility. The most obvious task is getting a new faculty member started. A new faculty person has financial requirements in both money and time. They need to have enough time to become successful. If you hire an established investigator and clinician, he or she will have been successful in obtaining funds and those funds will pay part of his or her salary. However, a new faculty member will not have that funding, and the department or institution needs to underwrite him or her for some period of time. New faculty members also need some seed money to buy animals, computers, paper, and pencils. For most people, this start-up time is somewhere on the order of 3 years. Most of the time, at about 2 or 3 years, they need some extra help in getting over the hump. They have data, some publications; they are almost there. They just need a little bit more to achieve external funding. In our department, we have an internal, intradepartmental grant program to support people specifically to get over the hump to get external funding. So, flexibility is necessary as you proceed.

\section{FACULTY DEVELOPMENT}

Now let me switch gears a little and suggest how to get a department or group of individuals started. This baseball analogy compares the Tony Guinn vs Cecil Fielder theory of hitting. Tony Guinn has been in the major leagues for 14 years. He gets the wood on the ball every time out. He gets singles, and singles, and singles, and not very many home runs. He has won the batting title a number of times. He is going to be in the Hall of Fame. Cecil Fielder, now with the New York Yankees, swings to the fences every time. He hits some home runs and he has led the major leagues in strikeouts the last 3 years in a row. $\mathrm{He}$ is not going to get in the Hall of Fame.

I think that young departments and young faculty members need to take the Tony Guinn theory of hitting. You need to get the wood on the ball. You need to get on base, steal second, move to third, and then score without trying to hit a home run. You need to start small. You initially need to apply for funding intramurally. You need to think short term. You need to think $\$ 15-25,000$ grants with local business or with the local American Heart Association. Then as you become more proficient, you should go for bigger and longer-term awards. You need to think of sources besides federal grants.

As an example, our EM faculty has been successful in receiving funds from General Motors. You would not expect a biomedical research institution to study trauma in Flint, Michigan. Our trauma service also has funding from General Motors to set up a trauma network in Flint, which is where General Motors has a lot of its business. Our urologists have a study to look at prostate cancer, because General Motors workers, many of them men, are retiring, and they are getting prostate cancer. So, think beyond the standard medical and pharmaceutical industry's role and also consider local industries and other local businesses.

For the heads of departments, start with your young faculty right away by spelling out what you expect. If research is going to be part of their lives, tell them it is part of the job expectation. You should have an explicit discussion before they are hired about how their time will be allocated to find awards and research work. Those 2 items will intersect. You need to have an explicit understanding about the seed money that you will give them. You need to have, as I mentioned, involvement of the collaborators in both their recruitment and their first years of academic life. Again, at the very beginning, you need to set up a mutual set of obligations. You need to tell them, I will do this for you and you will do this for me in my department. A year from now, you will have a grant from General Motors and in 2 years you will have a grant from the American Heart Association of Michigan and in 3 years you will send in your first award application. You need to review those deadlines periodically to make sure that they are being met. If they are not, you need to remind them. If they are, you need to pat them on the back.

Finally, I want to give you an overview of $\mathrm{NIH}$ funding and one way this could apply to EM. The NIH has a full series of awards that are relatively difficult to obtain. This is the sequence that I would use. Start with the awards called " $K$ " awards, which are titled "Mentored Clinical Scientist Development Awards." They are specifically designed to help clinical scientists become proficient at research and primarily have been used for bench research, but that is flexible. They are important because they not only judge the individual who is the researcher, they also judge the mentor. The person has to have his or her degree completed and it requires $75 \%$ effort, so this is a really serious time commitment. The mentor is judged more heavily, I believe, than the applicant. If you pick an established mentor, you are miles ahead. You cannot obtain the " $\mathrm{K}$ " awards if you have already been externally funded, but once you are, you can make a transition to other kinds of awards.

One step up in terms of this is called a First award. In this kind of circumstance, training is to have been completed. Persons are expected to not require mentoring, and they will have to stand on their own 2 feet. 
They will have been out of training for $<5$ years. The R29 Award requires $50 \%$ effort, equivalent to 20 hours of a 40-hour week. The award totals $\$ 350,000$ over 5 years $(\$ 70,000$ per year). It is just more stringent in terms of scientific content, and the individual is applying his or her judgment. These awards can be transitioned into " $R$ " awards, which are the main stage of funding. These are the most competitive, and most difficult, for a maximum of 5 years. You can ask for as much money as you want. You can put in any amount of effort, from $1 \%$ to $100 \%$.

\section{SUMMARY}

A research-based department is developed from a specific intentional process. It requires a commitment of time and money from the leadership and desire from the faculty. Faculty need to be taught and mentored. Research funding is achieved only through a careful, deliberate plan.

\section{REFERENCES}

1. Carden DL, Dronen SC, Gehrig G, Zalenski RJ. Funding strategies for emergency medicine research. Acad Emerg Med. 1998; 5:168-76.

2. Biros MH. Barsan WG, Lewis RJ, Sanders AB. Supporting emergency medicine research: developing the infrastructure. Acad Emerg Med. 1998; 5:177-84.

Key words: research; emergency medicine; research funding.

\section{Correction}

The location of New York University-Bellevue Hospital was listed as Flushing, NY, and should have been New York, NY, in a letter to the editor in the January 1998 issue of Academic Emergency Medicine (Lee ED, Rosenberg CR, Sixsmith DM, Pang D, Abularrage J. Does a physician-patient language difference increase the probability of hospital admission? [letter]. Acad Emerg Med. 1998; 5:86-9). 